\title{
A Formula of Potassium Polymer Sulfonated Drilling Fluid Developed based on Rock Microscopic Analysis
}

\author{
Sheng Wang ${ }^{1, *}$, Jinyong Zhu ${ }^{2}$, Jingfei Wang ${ }^{1}$, Liyi Chen ${ }^{1}$, Tongde Zhang ${ }^{3}$, Chuan Zhang ${ }^{4}$, Chaopeng Yuan ${ }^{5}$ \\ ${ }^{1}$ State Key Laboratory of Geohazard Prevention and Geoenvironment Protection, Chengdu University of Technology, \\ Chengdu, Sichuan China 610059 \\ ${ }^{2}$ Sichuan Provincial Chuanjian Institute of Investigation and Design, Chengdu, Sichuan China 610072 \\ ${ }^{3}$ Institute of Exploration Technology, Chengdu, Sichuan China 611734 \\ ${ }^{4}$ Southwest Jiaotong University, Chengdu, Sichuan China 611756 \\ ${ }^{5}$ Sichuan Shutong Geotechnical Engineering Company, Chengdu, Sichuan China 610081
}

\begin{abstract}
During the rapid coring drilling in the Wenchuan earthquake Fault Scientific Drilling project, the deep fault zone is characterized with extremely broken strata and strong creeping, which made the drilling tasks very difficult. The key technology to drilling success is a suitable drilling fluid system. To design such a drilling fluid system with desired properties, the mineral composition of rock samples from deep fault zone was analyzed using X-Ray Diffraction (XRD) and Fourier Transform Infrared (FTIR) absorption spectrum. Based on the results, a potassium-based polymer sulfonated drilling fluid was developed. This drilling fluid system possesses a variety of advantages including good quality of filter cake, strong anti-pollution ability, anti-collapse ability and inhibition ability, and great compatibility with treating agent. Also, the composition of this drilling fluid is simple, easy to prepare and at a relatively low cost. The study of potassium sulfonated drilling fluid system is of great significance for the rapid core drilling in deep fault zone.
\end{abstract}

Keywords: Wenchuan earthquake Fault Scientific Drilling Project, deep fault zone, X-ray Diffraction, Fourier Transform Infrared Absorption Spectroscopy, Potassium-based polymer sulfonated drilling fluid

\section{Introduction}

The Mw8.0 Wenchuan earthquake occurred on May 12, 2008 , has caused devastating damages in local areas, yet it has provided a unique opportunity and great challenges for the earthquake researchers to explore the features of seismic fault. Rapidly responding to this earthquake, the Ministry of Science and Technology of China and the International Continental Drilling Program collaboratively launched the Wenchuan earthquake Fault Scientific Drilling (WFSD) project in October 2008.

The WFSD includes four boreholes along the Wenchuan earthquake fault zone. The first drill hole (WFSD-1) was started on November 4, 2008, and the last (WFSD-4) was completed on February 11, 2014. During the drilling and construction processes, the complex strata in the fault-zone has caused many complicated situations and accidents, among of which the co-occurrence of collapses and shrinkages in boreholes, resulted from the broken strata and strong creeping was one of the major technical problems. Experts and technical staff have made various attempts to solve these complex issues, and certain fruitful results have been achieved. For example, Zhang et al (2014c) comprehensively reviewed the WFSD project, including finished hole conditions, technical problems encountered during the drilling and construction processes, drilling technology development and improvement, drilling engineering and management. Wu et al (2014) reported the drilling process and the key technologies used in WFSD-4. Focusing on the gouge drilling in WFSD-1, Li et al (2009) studied the features of drilling fluid systems, and contented that those possess properties of high density, low loss, low permeability and good lubrication are suitable for gouge drilling. Zhang et al (2014b) also summarized the properties and the scope of applications of the drilling fluid systems used in all WFSD holes, and proposed recommendations about the technology improvement in the deep and complex Earth's interior zone. Zhang et al (2014a), who chose potassium-based polymer sulfonated drilling fluid as the main drilling system, provided a detailed description about the using and maintaining situation of drilling fluid in each hole section, and in specific processes and the response measures of drilling fluid in complex situations.

Regarding fault materials, particularly fault gouge, international studies are mainly focused on fault gouge in a great depth. For instance, Warr et al (2014) employed FIBSEM technique to examine clay gouge from the creeping

* Corresponding Author: Sheng Wang, yongyuandewangsheng@sina.com, Phone: +(86) 189-0804-9520

Copyright (C) 2018 Canamaple Academia Services, http://press.camdemia.ca

DOI: 10.15273/ijge.2018.01.004 
section of the San Andreas Fault at $\sim 2.7 \mathrm{~km}$ depth. Spencer et al (2012) conducted luminescence experiments to test the age of gouge in San Andreas Fault in a depth of $2.6 \mathrm{~km}$. On the contrary, when study the Wenchuan earthquake fault zone, Chinese researchers are mostly focused on the Earth's surface gouge, yet with different technologies. Such as Xie et al (2013) conducted minerals Raman spectral analysis on the gouge from Wenchuan earthquake fault zone. Wang et al (2014) investigated the gouge from Wenchuan earthquake fault zone using XRD and FTIR. Yuan et al (2013) explored the microstructure and the clay minerals' characteristics and significance of the gouge from the northern section of Beichuan-Yingxiu fault zone. These works have gained valuable information and knowledge on the physical and mechanical properties or microscopic features of the Earth's surface gouge, and built a concrete foundation to further explore the characteristics of minerals in deep fault zone.

Normally, drilling fluid technologies employed in given fault zones or fault gouge sections is determined according to the actual problems encountered in the drilling field, which usually is relied solely on the operators' drilling experience. Despite that the microscopic characteristics of the stratum could provide valuable information in drilling fluid selection, however, few researches have been done in this respect.

Moreover, considering the extremely complex strata in deep fault zone, formulas for drilling fluid system are complex, and few of them are simple, practical and easy to prepare and adjust.

To solve these problems, undisturbed rock samples were obtained from WFSD-4 fault zone at a depth of 2,216 m through core drilling. Their mineral compositions were analyzed using X-Ray Diffraction (XRD) and Fourier Transform Infrared (FTIR) absorption spectrum. Based on the results, a potassium-based polymer sulfonated drilling fluid system was developed for deep fault-zone drilling.

\section{Microscopic Analysis of Rock Samples}

\subsection{Rock sample collection}

Rock samples were obtained from WFSD-4 (Figure 1a). This hole is located in Nanba town, Pingwu county, the northern section of Beichuan-Yingxiu fault zone, where has experienced a strong strike-slipping effect. The hole is finished with $2,338.77 \mathrm{~m}$ in depth and $150 \mathrm{~mm}$ in diameter.

Rock samples (Figure 1b) were obtained using screw motor-hydraulic hammer-long two halves tube drilling technology. Rock samples are black, plastic, soft, with advanced argillic alteration and contain many rock debris.

When the WFSD-4 borehole was drilled below 2,200 m, the strata are very complex. Because of their soft crush, it is easy to cause accidents - expansion and hole shrinkage, and collapse and hole enlargement occurred interactively. During the WFSD-4 drilling, roller bit fell once, drilling tool fell twice, plus there were five sticking accidents. The following problems were encountered during the deep fault-zone drilling:

(1) Due to the dispersed and plastic materials of the fault zone, and under the influence of ground stress and mechanical forces, creep, hole shrinkage and peeling off have occurred frequently;

(2) The small sized aperture used in the drilling led to a small ring space. So once hole shrinkage occurred, the circulation channel was easily to be blocked when pulling the drilling tool;

(3) There was little accurate information about the formation pressure in the strata, therefore the density of drilling fluid was difficult to adjust, which has resulted in hole creep and shrink.

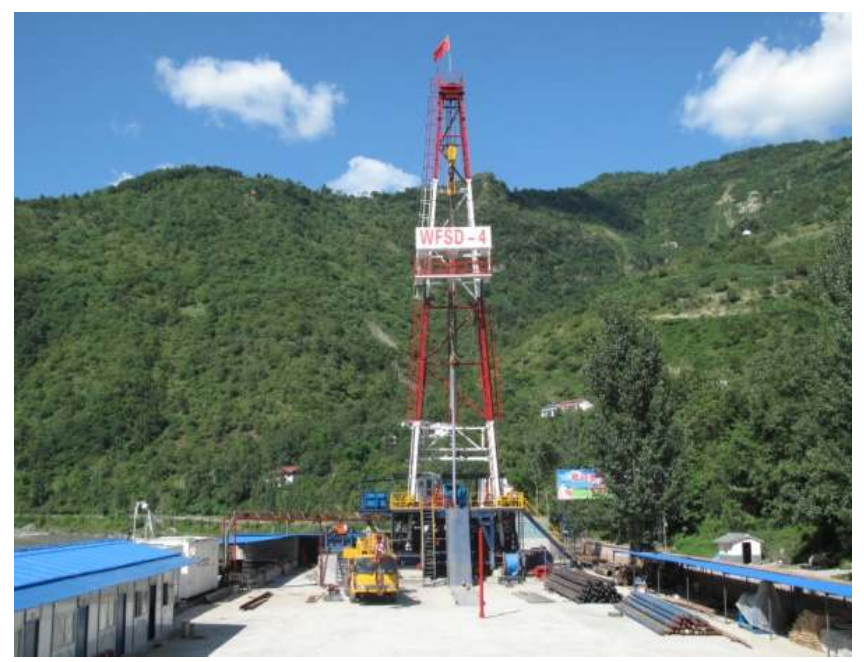

(a) WFSD-4

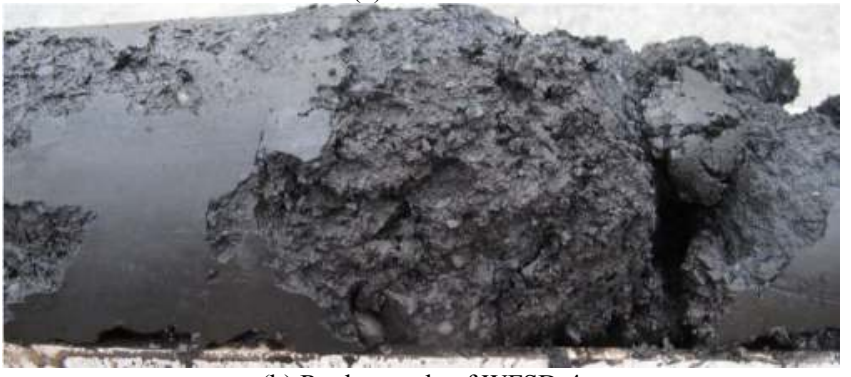

(b) Rock sample of WFSD-4

Figure 1 Wenchuan earthquake fault zone scientific drilling (WFSD-4) and rock sample

\subsection{Microscopic analysis of minerals in the rock samples}

\subsubsection{XRD experiment}

Rock samples were air dried, crushed to powder with particle sizes smaller than $44 \mathrm{um}$. A small amount of the powder was sent to the Materials and Chemical Engineering Comprehensive Laboratory at Chengdu University of Technology to conduct X-ray diffractometer test using a DX2700 XRD (Shanghai Precision Instrument Co., Ltd. Shanghai) with a copper target. Electric power applied in the test was $\leq 4 \mathrm{kw}$, tube voltage was $10 \sim 60 \mathrm{~V}$; step size was set at the smallest of $1 / 1000^{\circ}$, and a scanning speed at $0.0012^{\circ} \sim$ $70 \%$ min.

The XRD results is shown in Figure 2. Comparing with that of base rock and the standard PDF card, the main clay minerals in the rock sample are identified as quartz, illite, 
chlorite, feldspar, as well as a small proportion of calcite and pyrite.

The virgin rock of the rock sample is slate, its main mineral is mica. Other major minerals include chlorite, quartz, feldspar, and a small amount of pyrite and calcite. The illite in the rock sample is evolved from mica. If the sedimentary environment had been hot and humid, illite would have evolved into smectite by chemical weathering, even possibly into kaolinite following further decomposition (Srodon and Eberl 1984, Chamley 1989). But this process did not happen during the rock formation process in WFSD4 , which indicates that the chemical weathering has been inhibited in this fault zone at depth, and the environment of the fault zone was conducive to the preservation of illite. Different environment of fault movements can be reflected by different combinations of clay minerals. The combination of illite and chlorite reflects a dry and cold alkaline environment, and also a weak weathering process in the deep fault zone (Wu et al 2007).

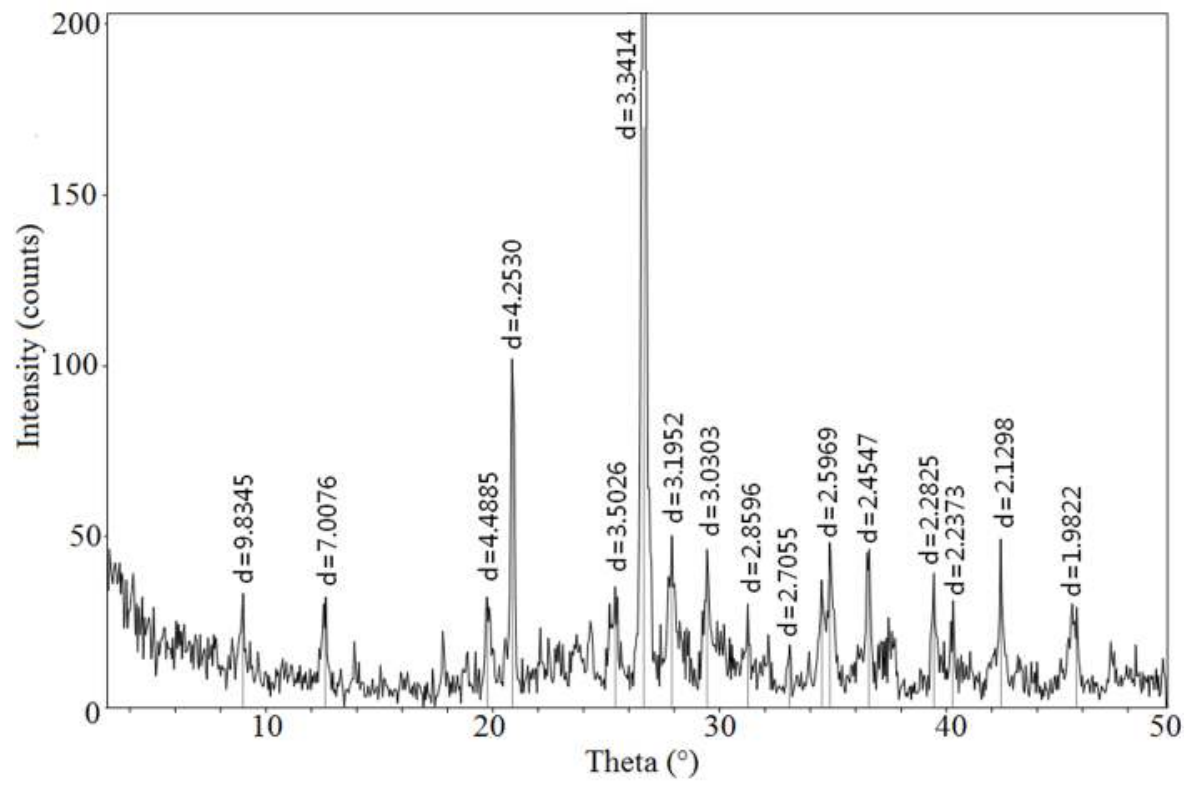

Figure 2 X-ray diffraction map of the rock sample from WFSD-4 deep fault

Illite has three polytype structures, namely $1 \mathrm{M}_{\mathrm{d}}, 1 \mathrm{M}$ and $2 \mathrm{M}_{1}$ (Wang et al 2003, Tohver et al 2008). Combining the result of XRD with standard PDF card, we found that the characteristic diffraction peaks $2.2373,3.1952,4.4885$, and 9.8345 belong to the $2 \mathrm{M} 1$ type structure, which indicates that the polytype structure of the illite is $2 \mathrm{M}_{1}$.

\subsubsection{FTIR experiment}

Some sample powder was further dried in oven to eliminate free water. Then dried powder was transferred to the State Key Laboratory of Polymer Materials at Sichuan University to conduct the FTIR test on a Nicolet 380 intelligent Fourier transform infrared spectrometer (Thermo Fisher Scientific Inc. USA), with two optional resolutions of $0.5 \mathrm{~cm}^{-1}$ (K type) and $0.9 \mathrm{~cm}^{-1}$ (L type). Spectral range is in mid-infrared (375 $\left.\sim 7,800 \mathrm{~cm}^{-1}\right)$.

The IR spectra map is shown in Figure 3. The absorption peaks appear at 467.4, 793.6, 999.7, 1,436.8, 3,419.0 and $3,608.4 \mathrm{~cm}^{-1}$, respectively. Table 1 shows the affiliations of rock compositions with the infrared absorption spectrum peaks. The strong absorption band around $467.4 \mathrm{~cm}^{-1}$ is related to the overlap region of Si-O bond of quartz and clay minerals. $793.6 \mathrm{~cm}^{-1}$ is the strong absorption peak of quartz, A strong absorption region at $999.7 \mathrm{~cm}^{-1}$ is due to the stretching vibration of $\mathrm{Si}(\mathrm{Al})-\mathrm{O}$ bond of clay minerals, of which a weak absorption shoulder appears at the high frequency side. An absorption peak at $1,436.8 \mathrm{~cm}^{-1}$ is resulted from the stretching vibration of $\mathrm{CO}_{3}{ }^{2-}$. The peaks at $3,419.0$ and $1,626.5 \mathrm{~cm}^{-1}$ are associated with the stretching vibration of $\mathrm{H}_{2} \mathrm{O}$. Since the dried rock sample has no free water, which means that the crystal layers of clay mineral contain adsorbed water, while chlorite is a typical layered hydrous silicate mineral. An absorption peak at $3608.4 \mathrm{~cm}^{-1}$ is the stretching vibration of hydroxyl (-OH) of clay minerals or mica.

The FTIR analysis of chemical bonds of fault minerals verifies the results of XRD analysis, and provides further evidence of the mineral compositions in the rock sample.

Table 1 The affiliations of the infrared absorption spectrum peaks

\begin{tabular}{|c|c|}
\hline $\begin{array}{c}\text { Peak } \\
\text { position/cm }{ }^{-1} \\
\end{array}$ & Affiliation \\
\hline 467.4 & Si-O $\rightarrow$ quartz and clay minerals \\
\hline 793.6 & $\mathrm{Si}-\mathrm{O}-\mathrm{Si} \rightarrow$ quartz \\
\hline 999.7 & $\mathrm{Si}(\mathrm{Al})-\mathrm{O} \rightarrow$ clay minerals \\
\hline 1,439 & $\mathrm{CO}_{3}^{2-}$ \\
\hline $3,412 \& 1,626.5$ & $\mathrm{H}_{2} \mathrm{O} \rightarrow$ chlorite \\
\hline 3,608 & $\begin{array}{c}\text { hydroxyl }-\mathrm{OH} \rightarrow \text { clay mineral or } \\
\text { mica }\end{array}$ \\
\hline
\end{tabular}




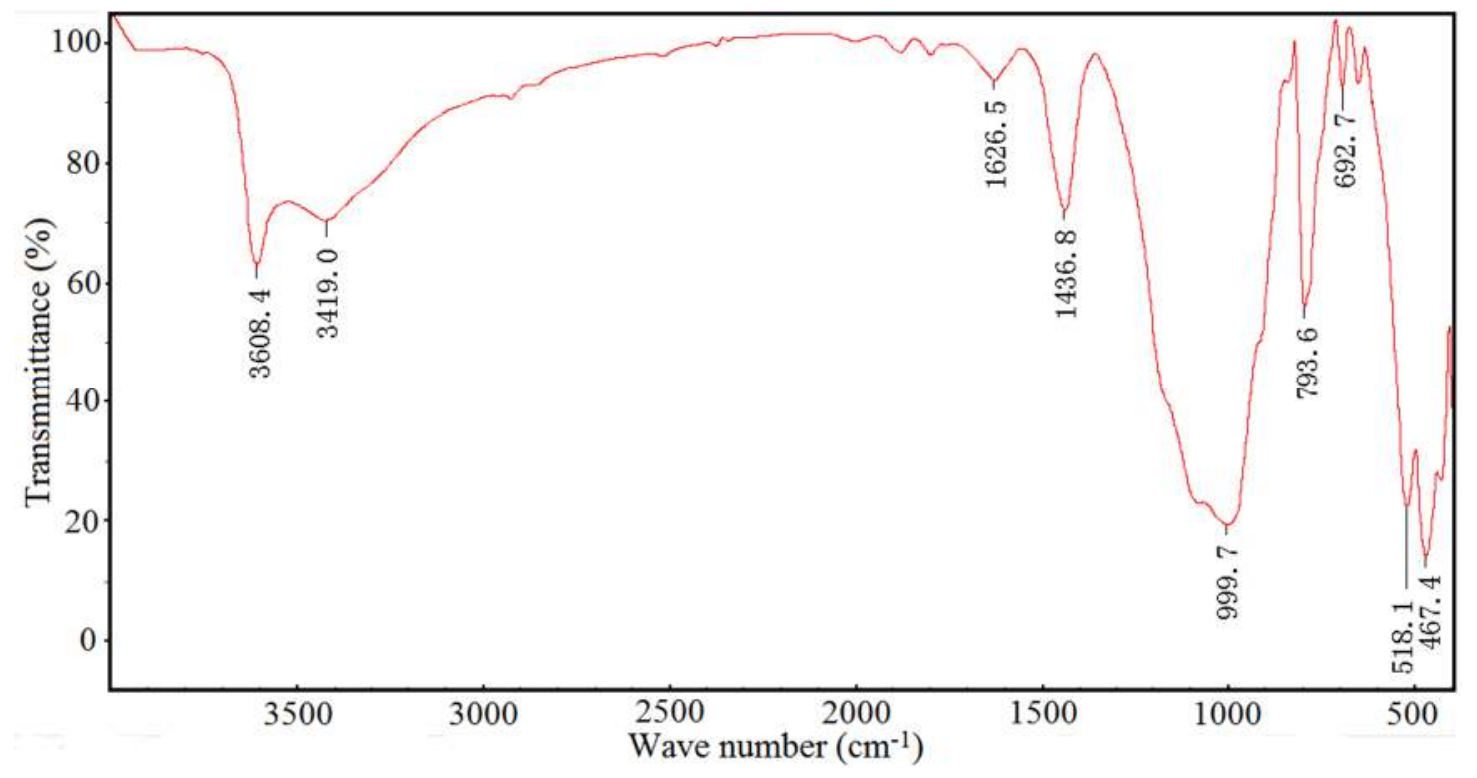

Figure 3 FTIR spectrum of the rock sample collected from WFSD-4

\subsection{Faulty zone characteristics}

The dry and alkaline sedimentary environment of fault zone is mainly reflected by illite and chlorite, which also mark a weak weathering intensity. The illite of $2 \mathrm{M}_{1}$ structure was transformed from $1 \mathrm{M}$ structure within a temperature range of $200 \sim 300{ }^{\circ} \mathrm{C}$. So, under high ground stress, the relative motion of the footwall and upper wall of the fault has generated high heat.

\subsection{Effects on drilling}

The microscopic analyses show that illite, quartz and chlorite are the main minerals in the rock. Generally, illite and chlorite exist in degradation state. Specifically, under a high stress condition, potassium ions extrude from the crystal layers of illite, which provides a favorable condition for water molecules to enter the crystal layers and makes illite hydrate and illite lattice swell. Due to a part of brucite having been removed, chlorite hydrates among the crystal layers and its lattice swelled to a certain degree, which is the degradation of chlorite. Therefore, hydration, expansion and hole shrinkage are easy to occur during the fault zone drilling.

The ground stress of Longmen mountain fault zone is unusually higher than other regions, and the difference between the maximum and minimum horizontal stresses is great. Moreover, the adjustable extent of equal yield density of drilling fluid is small. When the density of drilling fluid is smaller than the equal yield density of collapse pressure in the stratum, shear failure and rock collapse around the hole wall is easy to occur. Moreover, if the stratum is plastic, hole shrinkage will appear. However, when the density of drilling fluid is higher than the equal yield density of collapse pressure in the stratum, fluid loss is easy to occur. The hole stability of deep fault zone is extremely important, and the requirements of drilling fluid properties are extremely rigorous.

\section{Potassium-based Polymer Sulfonated Drilling Fluid}

\subsection{Selection of drilling fluid system}

The properties of water-based drilling fluid are mainly determined by the dispersion state of the clay particles, which is mainly determined by the surface state of the clay particles in water or drilling fluid, which in turn is mainly determined by the state of the interaction between treating agent and clay particles. When the deep fault zone was drilled, many complex situations occurred, such as severe crush, strong creep, $\mathrm{CO}_{2}$ gas leakage, collapse and hole shrinkage, which urgently demand drilling fluid to meet the following properties:

1) Superior anti-collapse capacity, low fluid loss, thin and tough mud;

2) Superior anti-pollution ability, stable performance;

3) Good compatibility, easy to adjust, good shear thinning behavior;

4) Good lubricity to reduce friction and the wear of drill tool;

5) Good suppression performance, good plugging performance, can avoid sticking due to hydration expansion and hole shrinkage;

6) The density of drilling fluid could be adjusted at any time to fit the strata with solid control equipment;

7) Simple to maintain, with reasonable environmental and economic cost.

$\mathrm{K}^{+}$in potassium-based polymer sulfonated drilling fluid, whose diameter is equal to that of hexagonal ring of siliconoxygen tetrahedron, is just embedded in the hexagonal ring, so that the hydration dispersion of shale and argillite is weakened. In addition, the cooperation of polymer and sulfonated treating agent can effectively inhibit the expansion of the strata, and then prevent collapse. Thus, the potassium-based polymer sulfonated drilling fluid could meet all requirements above. Therefore, we developed and 
further explored the potassium-based polymer sulfonated drilling fluid in drilling deep fault zone.

\subsection{Optimization design and performance evaluation}

\subsubsection{Immersion test}

To screen the treating agent and design the formula of drilling fluid, we conducted immersing expansion test on rock samples, and calculated their expansion rates after immersing in six typical solutions. The expansion rates were measured using a WZ-2 type no load dilatometer. Dried rock

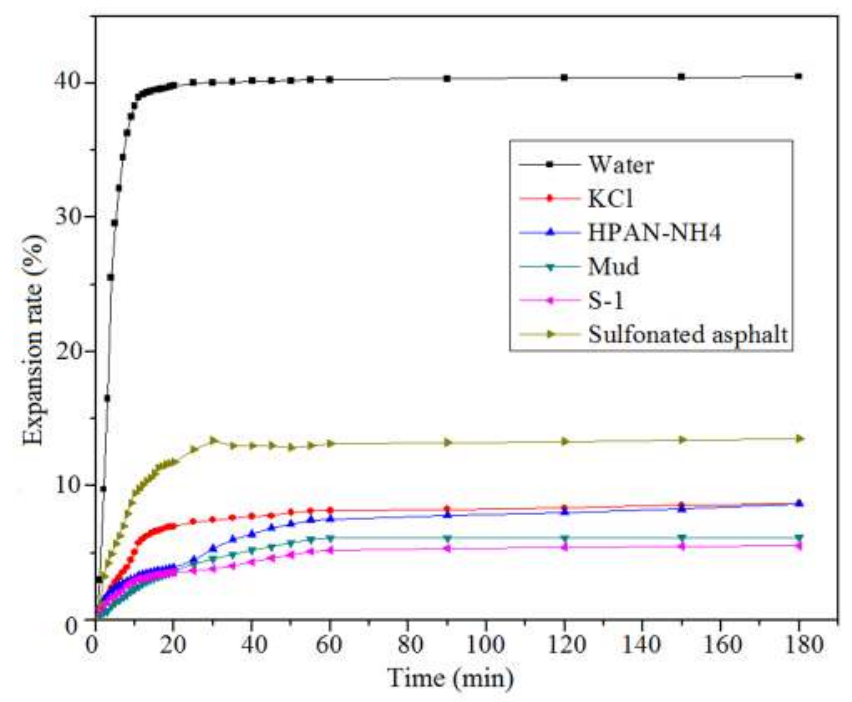

Figure 4 Rock example' expansion rates in different solutions samples were filtered to get powder with particle size smaller than $830 \mathrm{um}$. The powder was then divided and immersed into water, $20 \% \mathrm{KCl}$ solution, $20 \% \mathrm{HPAN}-\mathrm{NH}_{4}$ solution, $20 \% \mathrm{~S}-1$ solution, $20 \%$ sulfonated asphalt solution and base mud, respectively. Among of those, base mud was prepared using 4\% high-quality bentonite and water, and allowed 24 hours for hydration reaction before used in the test. Expansion rates of the samples immersed in the six solutions were observed and continuously recorded till a stable expansion state was achieved (Figure 4).

According to our experimental data (Figure 4), the rates of rock powder swelling are significantly different among the six soaking solutions. The fastest and greatest expansion was observed in water, in which the response curve quickly rises to about 40 percent within the first $10 \mathrm{~min}$, then followed with a gentle rising till the final expansion rate reaches to $40.7 \%$. The sulfonated asphalt solution experienced the second fastest expansion; the rest four solutions witnessed much slower expansions, their expansion rates, both within the first hour and the final are less than $10 \%$. The expansion rates within the first hour in the six solutions occurred in an order as follows: water $40.28 \%$, sulfonated asphalt $13.1 \%, \mathrm{KCl} 8.13 \%$, hydrolyzed polyacrylonitrile amine $7.5 \%$, base mud $6.1 \%$, and S- $15.2 \%$, and the final expansion rates are $40.7 \%, 14.25 \%, 8.78 \%$, $9.05 \%, 6.25 \%$ and $7.85 \%$, respectively.

\subsubsection{Screening treating agent}

Table 2 shows the functions and reference dosage of the main materials of potassium-based polymer sulfonated drilling fluid.

Table 2 The main materials of potassium-based polymer sulfonated drilling fluid

\begin{tabular}{llc}
\hline \multicolumn{1}{c}{ Materials treatment agent } & \multicolumn{1}{c}{ Functions } & Recommended dosages (\%) \\
\hline Na-bentonite & Tackify & $3 \sim 5$ \\
\hline $\mathrm{KCl}$ & Provide $\mathrm{K}^{+}$ & $5 \sim 10$ \\
\hline $\mathrm{KOH}$ & Adjust pH value, provide $\mathrm{K}^{+}$ & $5 \sim 10$ \\
\hline Potassium polyacrylate & Peridium, tackify & $1 \sim 3$ \\
\hline Biopolymer XC & Tackify & $1 \sim 3$ \\
\hline Sulfonated methyl lignite SMC & $\begin{array}{l}\text { Viscosity reducer for high temperature } \\
\text { resistance, filtrate reducer }\end{array}$ & $1 \sim 2$ \\
\hline Sulfonated methyl phenol resin SMP & $\begin{array}{l}\text { Viscosity reducer for high temperature } \\
\text { resistance, filtrate reducer }\end{array}$ & $3 \sim 5$ \\
\hline Sulfonated methyl tannins SMT & $\begin{array}{l}\text { Viscosity reducer for high temperature } \\
\text { resistance, filtrate reducer }\end{array}$ & \multirow{2}{*}{$0.5 \sim 1$} \\
\hline Sulfonated lignite resin SPNH & $\begin{array}{l}\text { Filtrate reducer for high temperature } \\
\text { resistance and salt tolerance }\end{array}$ & $1 \sim 2$ \\
\hline Superfine calcium carbonate & Plugging, increase density, lubrication & $3 \sim 5$ \\
\hline Cmc & Tackify, filtrate reducer & $2 \sim 3$ \\
\hline Modified asphalt & Stabilize borehole wall & $2 \sim 3$ \\
\hline Glub & Lubrication & \\
\hline Barium sulfate baso 4 & Increase density & \\
\hline
\end{tabular}


In order to select the main treatment agents in the drilling fluid system to meet the performance requirements for drilling fluid and characteristics of deep formation of WFSD-4 hole in Wenchuan earthquake fault zone, a Scanning Electron Microscope (SEM) analysis was taken on the core components of potassium-based polymer sulfonated drilling fluid, which is consisted of biopolymer (XC), sulfonated methyl lignite (SMC) and sulfonated methyl phenol resin (SMP). The SEM results provide a reference to guide the design of drilling fluid from a micro perspective (Figures 5, 6 and 7).

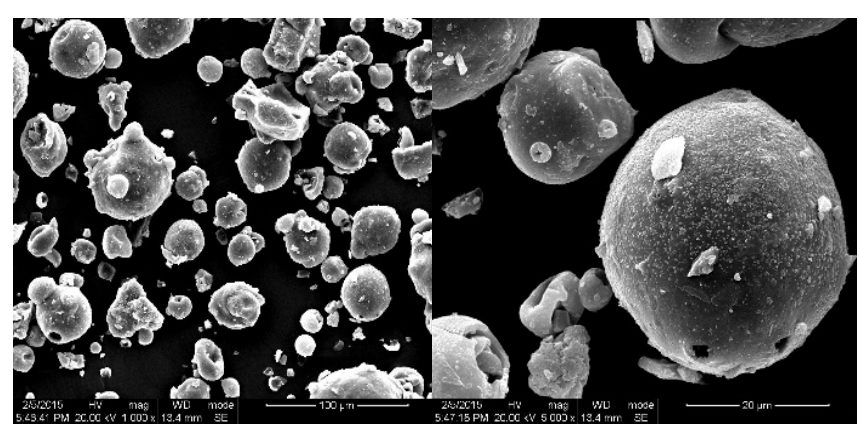

Figure 5 The SEM results of SMC

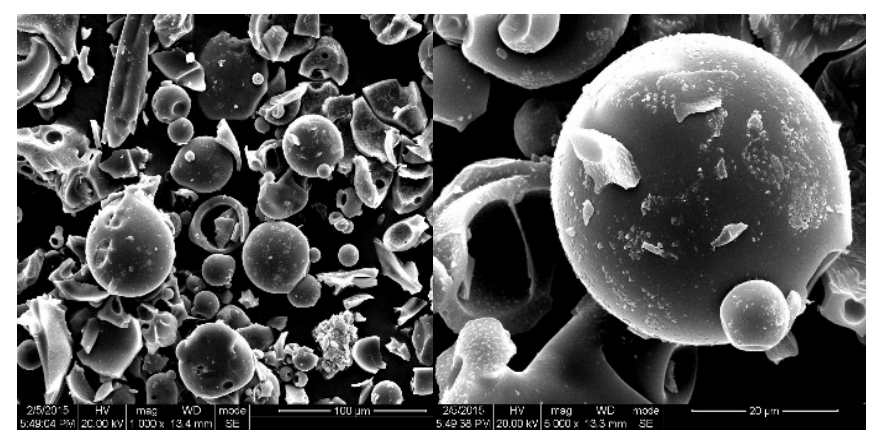

Figure 6 The SEM results of SMP

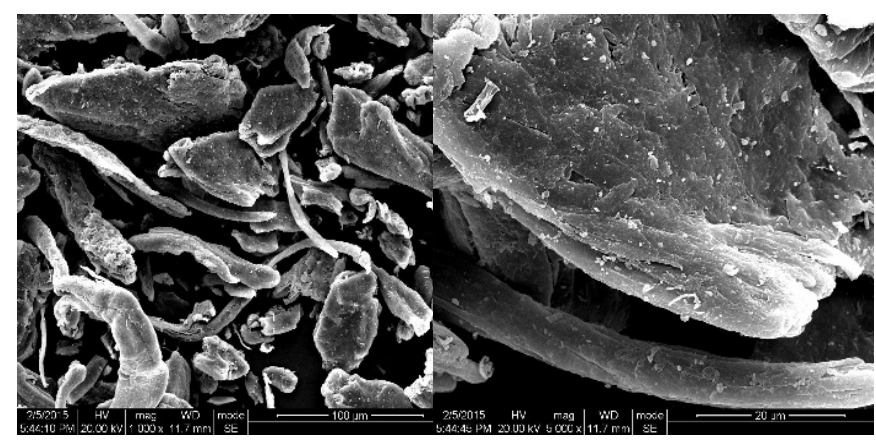

Figure 7 The SEM results of $\mathrm{XC}$

The function mechanism of the treating agents and the scanning electron microscope analysis show that the surface of clay particle adsorbed solvent water film by the hydrate group of SMC, meanwhile, the electric potential ( $\zeta$-potential) of clay particle is improved. That being said, SMC improves not only the mechanical resistance and electrostatic repulsion of the coalescence of clay particles, but also the coalescence stability of clay particles. Thus, the drilling fluid could form a dense mud cake to reduce fluid loss. The molecular structure of SMP is composed of benzene ring, methylene bridge and C-S bond. The adsorption groups of SMP molecular chain could form hydrogen-bonding adsorption with the oxygen of phenolic hydroxyl and clay particle surface. The hydrophilicity and salting-out resistance of SMP are strong, and it is barely affected by high temperature. $\mathrm{XC}$ is an excellent filtrate reducer. After being ionized in water, $\mathrm{XC}$ with multiple anionic group is easy to form hydrogen-bonding adsorption with the oxygen which is on clay particle surface. Thus, the adsorbed solvent water film is thickened, and its $\zeta$ potential is increased. Further than that, the electric double layer is thickened. Eventually, the mechanical resistance and electrostatic repulsion of the coalescence of clay particles are increased. In addition, the long chains of polymer could form multi-point adsorption with clay particles, and then form a structure net, which helps to improve the coalescence stability of clay particles, and has a protective colloid effect on clay particles. The long chains of macromolecular biopolymers have strong absorption capacity, and could form an adsorption film on the surface of the shale to prevent free water of drilling fluid from permeating through the strata. Therefore, it plays an important role in inhibiting hydration expansion.

Through the analysis above, the mixed use of the three treating agents, plus the anti-collapse property of $\mathrm{K}^{+}$, provides drilling fluid system with a good decomposition inhibition, good properties of viscosity reduction and filtration reduction, reasonable rheological parameters and shear thinning property. So $\mathrm{KCl}$ (in a concentration of $10 \%$ based on previous research experience) was selected to be the main inhibitor, the mixture of SMC and SMP was viscosity reducer and filtrate reducer, and $\mathrm{XC}$ was flow type modifier.

\subsubsection{Optimization formula and properties of drilling fluid}

Combined with the immersion tests and the SEM results of $\mathrm{XC}, \mathrm{SMC}$ and SMP, and through the indoor orthogonal tests (see Table 3), we obtained the following optimization formula of potassium-based polymer sulfonated drilling fluid:

base mud $+10 \% \mathrm{KCl}+2 \% \mathrm{XC}+3 \% \mathrm{SMC}+3 \% \mathrm{SMP}$ $+0.5-1 \%$ FKRH

The base mud is prepared using 5\% Na-bentonite, and stands for 24 hours; during this process, certain amount of weighting agent (barite) was added according to the situation. The main rheological property and filtration performance of the drilling fluid prepared by the optimization formula above are shown in Table 4.

The advantages of this drilling fluid include good quality of filter cake, strong anti-pollution ability, anticollapse ability and inhibition ability, and great compatibility with treating agent. Also, the composition of this drilling fluid is simple, and easy to prepare, the materials have broad sources to obtain and the cost is relatively low. During 
drilling in deep fault zone, we need to keep the properties of drilling fluid stable, which can be achieved by lower the polymer content and increase the sulfonation agent. We also should increase the dosage of inhibitor, namely the dosage of $\mathrm{KCl}$ reaches to $10 \%$, to ensure a reasonably particle size distribution of solid phase of the drilling fluid system and improve its overall anti-collapse performance. Because of the complexity of the drilling assembly of core drilling technology, we should try to reduce the viscosity and shearing force of the drilling fluid, the pressure loss in the cycle, and the aspiration pressure and thrilled pressure of boring tool in tripping operation. The control of solid-phase should be enhanced to reduce the unwanted solids content, which would contribute to reduce the tool wear and increase drilling efficiency.

\section{Conclusion}

(1) The rock samples were obtained from 2,216 m deep in WFSD-4 using screw motor-hydraulic hammer-long two halves tube. The rock samples were strongly plastic and soft, with small particle size and advanced argillic alteration.

(2) The rock samples were tested with XRD and FTIR. The results show that the main minerals of the WFSD-4 deep fault zone are quartz, illite, chlorite, feldspar, and with a small proportion of calcite and pyrite, which contribute to the borehole instability. These components also reveal a dry, cold and weak weathering alkaline sedimentary environment.
(3) Through the immersion test, screening treating agents and orthogonal experiment, the potassium-based polymer sulfonated drilling fluid system was developed, with the properties of simple composition, strong inhibition ability, small loss and good rheological property. Its formula is: base mud $+10 \% \mathrm{KCl}+2 \% \mathrm{XC}+3 \% \mathrm{SMC}+3 \% \mathrm{SMP}+$ $0.5-1 \%$ FKRH.

Table 3 Orthogonal factor level table of drilling fluid

\begin{tabular}{cccc}
\hline & \multicolumn{3}{c}{ Factor } \\
\cline { 2 - 4 } Test Number & $\mathbf{A}$ & $\mathbf{B}$ & $\mathbf{C}$ \\
\cline { 2 - 4 } & SMP-1 & SMC & XC \\
\hline 1 & $1(3 \%)$ & $1(3 \%)$ & $1(2 \% 0)$ \\
\hline 2 & $1(3 \%)$ & $2(4 \%)$ & $2(3 \% 0)$ \\
\hline 3 & $1(3 \%)$ & $3(5 \%)$ & $3(4 \% 0)$ \\
\hline 4 & $2(4 \%)$ & $1(3 \%)$ & $2(3 \% 0)$ \\
\hline 5 & $2(4 \%)$ & $2(4 \%)$ & $3(4 \% 0)$ \\
\hline 6 & $2(4 \%)$ & $3(5 \%)$ & $1(2 \% 0)$ \\
\hline 7 & $3(5 \%)$ & $1(3 \%)$ & $3(4 \% 0)$ \\
\hline 8 & $3(5 \%)$ & $2(4 \%)$ & $1(2 \% 0)$ \\
\hline 9 & $3(5 \%)$ & $3(5 \%)$ & $2(3 \% 0)$ \\
\hline
\end{tabular}

Table 4 The main rheological property and filtration performance

\begin{tabular}{ccccccccc}
\hline $\begin{array}{c}\text { Density } \\
\left(\mathbf{g} / \mathbf{c m}^{\mathbf{3}}\right)\end{array}$ & $\begin{array}{c}\text { Funnel } \\
\text { viscosity (s) }\end{array}$ & $\begin{array}{c}\text { Apparent } \\
\text { viscosity } \\
\text { (mpa. S) }\end{array}$ & $\begin{array}{c}\text { Plastic } \\
\text { viscosity } \\
\text { (mpa. S) }\end{array}$ & $\begin{array}{c}\text { Yield } \\
\text { point } \\
\text { (pa) }\end{array}$ & $\begin{array}{c}\text { Yield point and } \\
\text { plastic viscosity } \\
\text { ratio }\end{array}$ & $\begin{array}{c}\text { Fluid } \\
\text { loss (ml) }\end{array}$ & $\begin{array}{c}\text { Filter cake } \\
\text { thickness } \\
\text { (mm) }\end{array}$ & pH \\
\hline 1.17 & 37 & 23 & 18 & 6 & 0.33 & 4 & 1 & 9 \\
\hline
\end{tabular}

\section{Acknowledgements}

This research is supported by National Natural Science of China (Grants NO. 41272331 \& 51204027), the Key projects of Sichuan Provincial Department of Education (Grant No. 16ZA0099) and the State Key Laboratory of Geohazard Prevention \& Geoenvironment Protection (Grant NO. SKLGP2015Z010).

\section{References}

Chamley, H. 1989, Clay Sedimentology. Berlin Heideberg: Springer-Verlag 21-50, pp425 - 441.

Li, Z.J., L.Y. Chen, J. Jia, J.W. You and Q.Y. Cao, 2009. Research and application of drilling fluid system for fault gouge section of the hole WFED-1 of Wenchuan earthquake fault scientific drilling project. Exploration Engineering (Rock \& Soil Drilling and Tunneling), 36(12): 13 - 19. (in Chinese).

Spencer, J.Q.G., J. Hadizadeh, J.P. Gratier and M.L. Doan 2012. Dating deep? Luminescence studies of fault gouge from the San Andreas Fault zone $2.6 \mathrm{~km}$ beneath Earth's surface. Quaternary Geochronology, 10: 280 - 284.

Srodon, J. and D.D. Eberl, 1984. Illite. Reviews in Mineralogy and Geochemistry, 13(1): 495 - 544.

Tohver, E., A.B. Weil, J.G. Solum and C.M. Hall, 2008. Direct dating of carbonate remagnetization by 40Ar/39Ar analysis of the smectite-illite transformation. Earth and Planetary Science Letters, 274: 524 - 530.

Wang, H.J., J. Zhou, C.X. Liu and M.X. Zhu, 2003. Very low-grade metamorphism of the Meso-Neoproterozoic and the Lower Paleozoic along the profile from Huangtudian to Xianxi in the central-northern part of Hunan Province, China. Science in China Series D: Earth Science, 46(7): 672 - 682.

Wang, Z.Y., J.J. Cao, S.Y. Luo and Y.P. Liao, 2014. X-Ray diffraction and infrared spectrum analysis of fault gouge in Wenchuan seismic belt. Spectroscopy and Spectral Analysis, 34(5): 1416 - 1420. (in Chinese)

Warr, L.N., J. Wojatschke, B.M. Carpenter, C. Marone, A.M. Schleicher and B.A. van der Pluijm, 2014. A "slice-andview" (FIB-SEM) study of clay gouge from the SAFOD 
creeping section of the San Andreas Fault at $\sim 2.7 \mathrm{~km}$ depth. Journal of Structural Geology, 69: 234 - 244.

Wu, M., S.R. Li, F.Y. Chu, J.P. Long and W.H. Tan, 2007. The assemblage and environmental significance of clay minerals in the surficial sediments abound Hainan island. Journal of Mineralogy and Petrology, 27(2): 101 - 107. (in Chinese)

Wu, J.S., W. Zhang, X.D. Li, X.Q. Duan and F.J. Ren, 2014. Overview on the drilling operation of and key technologies used in the WFSD-4 of Wenchuan earthquake fault scientific drilling project. Exploration Engineering (Rock \& Soil Drilling and Tunneling), 41(9): 120 - 125. (in Chinese)

Xie, C., B.G. Zhou, J.G. Du, L. Yi, and Z.W. Chen, 2013. Characteristics of Raman spectra of minerals in gouge of the Wenchuan earthquake fault zone. Spectroscopy and Spectral Analysis, 33(6): 1562 - 1565. (in Chinese)

Yuan, R.M., B.L. Zhang, X.W. Xu and C.Y. Lin, 2013.
Microstructural features and mineralogy of clay-rich fault gouge at the northern segment of the YingxiuBeichuan fault, China. Earthquake Geology, 35(4): 685 - 700. (in Chinese)

Zhang, L.S., L.Y. Chen, G. Peng and T.D. Zhang, 2014a. The drilling fluid technology in WFSD-4 of Wenchuan earthquake fault scientific drilling project (Rock \& Soil Drilling and Tunneling), 41(9): 146 - 150. (in Chinese)

Zhang, T.D., L.Y. Chen, J. Jia and Q.G. Li, 2014b. The drilling fluid technology and application of Wenchuan earthquake fault scientific drilling project. Exploration Engineering (Rock \& Soil Drilling and Tunneling), 41(9): 139 - 145. (in Chinese)

Zhang, W., S.Y. Hu, J. Jia, L.S. Fan and W. Zheng, 2014c. Implementation summary of drilling engineering of Wenchuan earthquake fault scientific drilling project. Exploration Engineering (Rock \& Soil Drilling and Tunneling), 41(9): 94 - 99. (in Chinese) 